\title{
A educação de surdos e cegos na França e no Brasil
}

\author{
The education of the deaf and blind in France and Brazil \\ La educación de sordos y ciegos en Francia y en Brasil
}

\section{* Roberta Baessa Estimado \\ Graduação pela Universidade de São Paulo, São Paulo, São Paulo, Brasil. roberuta@gmail.com - http://orcid.org/0000-0003-1016-0983 \\ ** Cássia Geciauskas Sofiato \\ Doutora pela Universidade Estadual de Campinas (UNICAMP), Campinas, São Paulo, Brasil. cassiasofiato@gmail.com -http://orcid.org/0000-0001-5291-9658}

Recebido em 03 de março de 2018

Aprovado em 05 de fevereiro de 2019

Publicado em 06 de maio de 2019

\section{RESUMO}

A discussão sobre a trajetória histórica da educação de surdos e cegos no Brasil ainda é necessária, tendo em vista que o discurso que os transformou em sujeitos passivos que teriam sido agraciados pela benevolência de "grandes homens" ainda ecoa nos dias atuais. Nesse sentido, a presente pesquisa objetiva apresentar o contexto do surgimento da educação de surdos e cegos na França no século XVIII e no Brasil do século XIX e delinear os impactos que a educação francesa de surdos e cegos provocou na educação brasileira para tal público alvo. O recorte temporal estabelecido para o estudo foi de 1760 a 1890 na França e de 1854 a 1890 no Brasil. Para tanto, foi realizada uma pesquisa bibliográfica e documental. Por meio da investigação concluímos que os procedimentos estabelecidos na França, referentes à educação de surdos e cegos nas primeiras instituições educacionais destinadas a tal público, impactaram significativamente 0 Brasil nos aspectos administrativo, de gestão e principalmente no que tange ao trabalho pedagógico desenvolvido no período em questão.

Palavras-chave: Educação de surdos; Educação de cegos; Educação Especial

\section{ABSTRACT}

The discussion about the historical trajectory of the education of the deaf and blind in Brazil is still necessary, since the discourse that transformed them into passive person who would have been graced by the benevolence of "good men" still currently echoes. In this sense, this research aims at presenting the context where the education for deaf and blind people started in France, in the 18th century, and in Brazil, in the 19th century. It will also define the impacts the French education for deaf and blind people caused in the Brazilian education for the same target audience. The period established for the study is from 1760 to 1890 in France and from 1854 to 1890 in Brazil. In order to do so, a bibliographical and documental 
research (GIL, 2002) was carried out. Through the investigation, we concluded that the procedures established in France for the education of deaf and blind people in the first educational institutions target at such audience has caused a significant impact in the administrative, managerial and, mainly, pedagogical aspects of the work developed at that time in Brazil.

Keywords: Education of the deaf; education of the blind; special education.

\section{RESUMEN}

La discusión acerca de la trayectoria histórica de la educación de sordos y ciegos en Brasil es aun necesaria, puesto que el discurso que los transformó en sujetos pasivos que fueran agraciados por la benevolencia de los "grandes hombres" sigue resonando en nuestros días. En este sentido, la presente investigación objetiva presentar el contexto des surgimiento de la educación de sordos y ciegos en la Francia del siglo XVIII y en Brasil del siglo XIX, e delinear los impactos que la educación francesa de sordos y ciegos provocó en la educación brasileña para los mismos. El recorte temporal establecido para el estudio fue desde 1760 hasta 1890 en Francia y desde 1854 hasta 1890 en Brasil. Para eso, fue realizada una investigación bibliográfica y documental. Con la investigación concluimos que los procedimientos establecidos en Francia, referentes à la educación de sordos y ciegos en las primeras instituciones educacionales destinadas à este público, impactaran considerablemente el Brasil en los aspectos administrativo, de gestión y sobre todo en lo que respecta al trabajo pedagógico desarrollado en este período.

Palabras clave: Educación de sordos; Educación de ciegos; Educación Especial.

\section{Introdução}

No âmbito do Brasil, vários autores empreenderam pesquisas sobre a educação de surdos e cegos, considerando o século XIX como um marco de referência, a saber: Mazzotta (2001), Zannuzi (2004), Soares (1999), Reily (2004), Rocha (2007), Sofiato (2011), entre outros. Nesse sentido, muitos processos históricos foram analisados, mas o campo tem se mostrado muito propício para novas investigações, frente à possibilidade de outras análises a partir da explanação de temas distintos com o uso de fontes primárias. A menção à França, no processo de surgimento das instituições brasileiras em alguns estudos aparece, entretanto, se faz necessário aprofundar essa relação, dada a importância histórica presente nesse contexto.

Este estudo objetiva apresentar o contexto do surgimento da educação de surdos e cegos na França no século XVIII e no Brasil do século XIX e delinear os impactos que a educação francesa de surdos e cegos provocou na educação brasileira para tal público alvo. O recorte temporal estabelecido para a abordagem das trajetórias foi de 1760 a 1890 
na França e de 1854 a 1890 no Brasil, períodos em que se instituíram as fundações e as primeiras gestões. Tal recorte foi estabelecido em função da variedade de fontes selecionadas para o estudo e sua correlação com os objetivos da pesquisa em questão.

Para tanto, a realização desta pesquisa foi orientada, a grosso modo, pela leitura, análise e confrontação do corpus documental selecionado, após um longo trabalho de levantamento e coleta das fontes. O seu conjunto é de grande riqueza, tanto por sua periodicidade, pois recobre, tanto no Brasil quanto na França, praticamente todo o período estudado com alguma regularidade, quanto por sua diversidade, apesar de se tratar, sobretudo, de fontes oficiais, a variedade de aspectos da instituição tratados pela documentação é bastante múltipla.

Com efeito, ao refletir sobre as possibilidades de uma história da educação comparada, trabalhamos as escolas de surdos e cegos francesas debruçando-se, especialmente, em algumas similitudes, estabelecendo um terreno comum de análise, sem deixar de reconhecer as singularidades construídas historicamente por cada um destes institutos (VIDAL, 2001). Entendendo que as fronteiras estão postas por limites epistemológicos muito mais do que pela própria geografia, o historiador deve aceitar o desafio de construir comparáveis (DETIENNE, 2004).

Assim, no processo de reinterpretação da história, almejou-se, com base na análise da documentação levantada e enfrentando o árduo desafio da comparação, somar aos trabalhos já produzidos sobre a temática até o presente momento, valorizando as conexões dos processos de institucionalização escolar para surdos e cegos no Brasil e na França, além de vislumbrar novos horizontes e questionamentos para a continuidade dos estudos sobre a história da Educação Especial em ambos os países.

\section{O Instituto Nacional de Surdos-Mudos de Paris (1760 a 1890)}

Até o século XVIII, ensinar os surdos a falar, ler e escrever parecia unanimemente complexo: são poucas as experiências de educar surdos anteriores ao final do período medieval que tiveram seus registros encontrados. Com efeito, os consagrados "pioneiros" na instrução de surdos eram, sobretudo, preceptores de crianças de famílias ricas das principais sociedades europeias, que realizavam um ensino individualizado, baseado na educação pela palavra. Desse modo, o suposto encontro fortuito do abade Charles-Michel de l'Épée com duas gêmeas surdas teria sido o responsável por uma inversão na abordagem realizada por estes preceptores até aquele momento. 
O Instituto Nacional de Surdos Mudos de Paris tem seu embrião em 1760, a partir do trabalho iniciado pelo abade Charles-Michel de L'Epée, na sociedade parisiense da segunda metade do século XVIII. As informações sobre o abade são raras e, em sua maioria, controversas. Sabe-se que ele nasceu na cidade de Versalhes no ano de 1712. Seu pai, Charles François Lespée era arquiteto do rei e sua mãe, Marguerite Varignon, era filha de um grande empreiteiro, ligado oficialmente à construção dos edifícios do rei Luís XIV. Nesse sentido, seu lugar social fica evidenciado: um dos filhos de uma família burguesa tradicional do século XVIII, estudou teologia e direito e decidiu seguir o caminho religioso (BÉZAGU-DELUY, 1990). L'Épée tinha, na data de criação de sua escola, 50 anos, uma carreira eclesiástica modesta e bastante conturbada, além de uma fortuna pessoal considerável. Com efeito, o abade era uma figura de destaque na sociedade parisiense da época, um homem ilustrado.

Assim, em 1771, com seus próprios meios, fundou a Instituição Nacional de SurdosMudos de Paris, na sua própria casa, localizada a rua des Moulins, recebendo as crianças pobres em regime de internato (BERNARD, 2014). A chave matriz para o sucesso e o reconhecimento internacional do trabalho desenvolvido por L'Épée com os surdos está nos chamados por ele exercícios públicos dos surdos e mudos. Tratava-se de demonstrações que ele organizava com seus melhores alunos, visando impressionar possíveis espectadores afortunados que pudessem se interessar em financiar a educação dessas crianças e promover a publicidade do abade e o reconhecimento de seu método de ensino. Para isto, ele mesmo convidava muitos espectadores célebres, fossem franceses ou estrangeiros, notadamente duques, embaixadores, eclesiásticos, entre outros, que enchiam a sala de lições durante as duas horas de demonstração (L'ÉPÉE, 1776). Estes exercícios teriam assumido um papel central no desenvolvimento da educação de surdos pelo mundo, que passaria a se desenvolver rapidamente a partir dali. Isso porque representantes de diversas nações passariam, a partir das aulas de L'Épée, a entrar em contato com essa nova possibilidade para instruir as crianças surdas.

Ademais, teria sido justamente com essa divulgação de seu trabalho na corte francesa que ele teria conseguido um espaço no Convento dos Celestinos, juntamente com uma pensão real, para criar sua própria escola de surdos. Quando ele morreu, em 1789, vários de seus alunos já se distinguiam na sociedade parisiense. Com efeito, a Assembleia Constituinte reconheceu, em 1791, a importância de sua obra, elevando a escola à 
categoria de Instituto Nacional, o que a tornaria a primeira escola oficial para surdos no mundo todo. L'Epée foi substituído, após a sua morte, pelo abade Roch-Ambroise Cucurron Sicard, que já havia fundado, anos antes, a escola de surdos de Bordéus. O desejo expresso de L'Épée era que a direção do Instituto fosse assumida por seu aluno mais próximo, Jean Masse, entretanto, o abade Sicard ganhou o concurso realizado entre os interessados pelo cargo e acabou ficando à frente do instituto até 1822, quando faleceu.

Sicard era uma figura controversa, proclamava-se monarquista e, por isso, foi conduzido em 1793 ao tribunal revolucionário e só conseguiu escapar da guilhotina com os relatos de seus alunos sobre suas ações de beneficência com a educação de surdos (BUTON, 1999). Além disso, teria sido o grande responsável pela descontinuidade do método do abade de L'Épée, que seria retomado somente na gestão de Périer, passando por novos períodos de descontinuidades nas gestões seguintes. Assim, no período que compreende a saída de Sicard (1822) e o início da administração de Léopold Ernest Javel (1885), isto é, em pouco mais de 60 anos, o instituto teve nove diretores, que refletiam, sobretudo, a instabilidade política do país ao longo do século.

No período que compreende a fundação do instituto e a saída do abade Borel (17711831), vislumbrando uma tendência ligada à ideia de que a educação de surdos deveria ser confiada aos religiosos perpetuada por meio da lógica de caridade intrínseca ao processo de criação da escola, todos os diretores da instituição foram abades. Ora, não estamos dizendo com isto que o caráter beneficente atribuído ao instituto em sua criação tenha sido um determinante ao longo de toda a sua trajetória, mas sim ressaltando que a concepção da educação de surdos como caridade permaneceu ainda em boa parte do século XIX, evidenciada aqui na escolha dos diretores.

Com a restauração e a Monarquia de Julho (1830-1848), a alta burguesia francesa ganha proeminência em detrimento da antiga ideia do direito divino dos monarcas, fazendo com que a Igreja imbricasse em um processo contínuo de perda de poder naquela sociedade. Isso significaria, para o Instituto, um período que percorreria todo o restante do século XIX em que os instituidores passariam a ser homens da administração, fossem antigos diretores de liceus, prefeitos ou funcionários gerais do Ministério do Interior. Assim, as antigas referências de pioneirismo a L'Épée e seu método gestual começam a perder espaço na primeira administração não-religiosa: Désiré Ordinaire, que havia sido professor de história natural da Faculdade de Ciências de Besançon, tenta, como uma de suas 
primeiras medidas, generalizar o método oral no Instituto, que ele havia observado nas escolas suíças.

A tensão entre os métodos orais e os métodos gestuais vai perpassar toda a história da instituição. Para o século XIX, o desfecho dessa disputa está expresso na decisão do Congresso de Milão em 1880, em que se define a interdição da língua de sinais como modo de ensino e de comunicação nas instituições escolares (PRESNEAU, 2009, p. 221). Assim, o instituto passaria por uma descaracterização da ideia inicial do abade de L'Épée: de instruir os surdos a partir dos sinais metódicos, de modo simultâneo. O Instituto Nacional dos Surdos-Mudos se tornou, nas últimas décadas do XIX, mais uma escola oralista, renegando a trajetória que outrora Ihe dera vida.

\section{O Instituto Nacional de Meninos Cegos de Paris (1760 a 1890)}

O Instituto Nacional dos Meninos Cegos de Paris tem sua origem com os trabalhos de Valentin Haüy, em um processo bastante similar ao realizado por L'Épée. O mito fundador de que Haüy teria encontrado próximo à Igreja Saint-Germain-des-Près um jovem cego e, sensibilizado, começou a estudar possibilidades para instruí-lo remonta diretamente à história de L'Épée com as gêmeas surdas. Há ainda outras versões, como o dia em que ele teria visto uma festa com cerca de dez cegos na feira de Saint-Ovide, em que os cegos emitiam sons incoerentes dos instrumentos que tocavam. Emocionado e indignado com o espetáculo, ele teria decidido ali que precisava ajudar os cegos a desenvolver o toque e afinar o ouvido, valorizando seus outros sentidos para sair da condição de ignorância em que eles se encontravam (GUILBEAU, 1907).

Contudo, as cartas de Valentin Haüy estudadas por François Buton e Pierre Henri nos relevam o aspecto central para a compreensão de seu interesse pelos cegos: Haüy era um frequentador recorrente dos exercícios públicos dos surdos-mudos realizados por L'Épée e não escondia o seu interesse pelo trabalho do abade. Inferimos, com efeito, que o interesse de Haüy pela educação dos cegos teria advindo, sobretudo, da constatação da notabilidade adquirida por L'Épée com seu método.

Vale ressaltar aqui que estas duas instituições se constituíram de iniciativas particulares, em que o instituidor nasceria como uma figura fundamental para a compreensão do seu processo de criação. O interesse em tornarem-se instituidores vinha, sobretudo, de almejar pertencer a nebulosa rede de sociabilidade que se configurava entre os filantropos e que, baseada no discurso de "amor à humanidade", ligava boa parcela dos 
homens notáveis da sociedade parisiense em relações políticas e religiosas repletas de especificidades (DUPRAT, 1995). Nesse sentido, entendemos que, tanto Charles Michel de L'Épée quanto Valentin Haüy tiveram suas motivações conectadas a essa lógica de notabilidade dos filantropos e, com efeito, no caso de Haüy, esse interesse fica evidente em seus relatos de admiração sobre o trabalho de abbé de L'Épée (HENRI, 1984).

Ao contrário de L'Épée, Valentin Haüy vinha de uma família pobre. Nascido em 1745 em Saint-Just-en-Chaussé, na Picardia, ele vai a Paris realizar seus estudos clássicos, obtendo um desempenho de bastante destaque no estudo das línguas, dominando cerca de 12 línguas. A sua vida esteve muito ligada à de seu irmão mais velho, Réné-Just Haüy. Réné era um abade que adquiriu bastante notabilidade social, não por seus trabalhos eclesiásticos, mas pelos estudos que ele desenvolveu na mineralogia sobre a geometria dos cristais, sendo considerado um dos fundadores da cristalografia. Assim, entendemos que a partir admiração de Valentin pelos estudos seu irmão e, especialmente, pelo status social que ele estava alcançando, suas pretensões estavam ligadas a um desejo de inserção social entre os notáveis homens das luzes da sociedade parisiense. (HENRI, 1984).

Valentin se aproveita do lugar social de seu irmão para que seu projeto seja colocado em prática. Réné era membro da Academia de Ciências e começaria a se aproximar da Sociedade Filantrópica almejando fundos para o projeto de seu irmão. Primeiramente, Valentin apresenta seu sistema de letras em relevo e seus primeiros alunos para a própria Academia de Ciências e, com o apoio de Réné, conquista uma pensão real para abrir uma escola com mais de 50 alunos. Ele teria, a partir disso, reconhecimento por seu trabalho quando, no ano seguinte, decide apresentar seus alunos ao rei no palácio de Versalhes, em uma tentativa similar a dos exercícios públicos de L’Épée (GUILBEAU, 1907).

Se o seu interesse era de inicialmente ensinar aos cegos a leitura, por meio de seu método de letras em relevo, ele também se preocupava em ensinar ocupações a eles, almejando uma possível emancipação por meio de trabalhos como o tricô, cordoaria, produção de cintos e redes, entre outras atividades manuais (GUILBEAU, 1907). Haüy escreveu e publicou uma obra intitulada Essai sur l'Éducation des Aveugles, com intuito de apresentá-la à corte e ter seu instituto elevado à categoria de Nacional. Entretanto, como a França estava às vésperas da revolução, seu plano não se concretiza. Assim, anos depois, 
ele acaba negociando com a Assembleia Constituinte um espaço no Convento dos Celestinos, onde já estava instalada a Instituição Nacional dos Surdos-Mudos.

O período em que surdos e cegos estiveram juntos no espaço do antigo Convento dos Celestinos é estimado entre dois a três anos. Todavia, foi um tempo de grandes conflitos e intensas disputas entre Haüy e Sicard visto que os dois dirigentes tinham posições políticas divergentes no seio das perturbações revolucionárias (BUTON, 1999, p. 99). Em 03 de abril de 1794, os surdos partem para se instalarem no edifício à Rua Saint-Jacques e, após alguns meses, os cegos também são transferidos, desta vez para o hospício "Catherinettes" (BUTON, 1999, p. 268-281).

Entre os anos de 1795 e 1815, o instituto passa por uma grande reformulação de sua ideia nacional: a Convenção determina que a ele aceitaria, a partir deste momento, somente cegos que estivessem aptos a trabalhar, assumindo o caráter de um ateliê (GUILBEAU, 1907). Entretanto, Haüy segue na direção da Instituição, o que permite que ela não sofra uma alteração substancial nas práticas de ensino: mesmo enfocando nos trabalhos manuais, o Instituto continua ensinando os cegos a leitura e as aulas de música, por exemplo (DIDIER-WEYGAND, 2003, p. 270). Alguns anos depois, o Instituto perderia o seu caráter inicial: Haüy é retirado da direção e seus alunos seriam reunidos no hospício dos Quize-Vingts por uma determinação do Ministério do Interior. Assim, ele teria perdido a sua função escolar, entrando em um período de declínio, retomando sua concepção inicial somente anos depois, com a intervenção direta de Napoleão. $\mathrm{Na}$ restauração das monarquias, Haüy reestabelece relações com a coroa, conseguindo recuperar sua escola, fazendo com que o Instituto assumisse o tão esperado título de "Nacional" (DIDIERWEYGAND, 2003, p. 281).

Com a volta dos Bourbons, ainda que a autonomia dos cegos tenha sido recuperada, a escola passaria ainda por momentos de instabilidade. A direção foi assumida pelo antigo médico do Instituto, Sébastien Guillé, que se limitava a prestar contas de sua administração ao Ministério do Interior e a aplicar suas ideias médicas na educação dos cegos. Ele passou cinco anos à frente da instituição, sendo retirado pelo ministério após denúncias de negligência (HENRI, 1984, p. 159). Em 1821, o doutor Alexandre-Réné Pignier o sucede. Observamos aqui uma tendência diferente à assumida na escola de surdos. Enquanto a concepção de instituição escolar foi mantida durante toda a trajetória do Imperial Instituto 
dos Surdos-Mudos, apesar de algumas descontinuidades, os cegos passaram um longo período destinado à prática do trabalho.

Contudo, Pignier decide receber Haüy com o objetivo de recuperar o projeto educativo do instituto, o que ele tenta fazer ao longo de sua gestão. Assim, ele se esforça para que os métodos para educar os cegos, sobretudo aqueles ligados à leitura e escrita, retomassem seu espaço dentro da instituição (DIDIER-WEYGAND, 2003, p. 283). Concomitante a isto, os sistemas alternativos de escrita para os cegos começavam a ser desenvolvidos no país. Naquele momento, o destaque estava para o método de Barbier, em que existiam "combinações de sinais simples representando as letras e os sons segundo um quadro predefinido que o aluno deve decorar. Um dentre eles é um método de escrita de pontos" (DIDIER-WEYGAND, 2003, p. 539-540), que remetiam aos sons e às letras somente por meio da combinação de pontos. Assim, ainda no ano de 1821, Barbier aceita introduzir o seu método no Instituto, recuperando os métodos de aprendizagem que tinham relevância no tempo de Haüy.

Neste momento em que o método de Barbier começava a ser ministrado aos alunos, Louis Braille, um deles, tinha a idade de 12 anos. Ele realizou uma profunda pesquisa sobre o método de Barbier (HENRI, 1952, p. 36-37) e, aos 20 anos de idade, ele publica seu alfabeto em pontos de relevo, suprimindo definitivamente o método de Barbier e ganhando projeção internacional, sendo a forma mais aceita de instruir os cegos à leitura e a escrita até os dias de hoje.

Em 1840, Joseph Guadet assume a direção do Instituto, na qual ele passaria os trinta anos subsequentes. Historiador, ele publica uma das obras mais conhecidas e reproduzidas no mundo sobre a história da Instituição, intitulada Institut des jeunes aveugles de Paris, son histoire, e o conhecido jornal L'instituteur des aveugles, que teria circulado pelas escolas de cegos de todo o mundo. Guadet se utilizava do jornal para estabelecer relações com os institutos de cegos por todo o mundo, visando promover a educação dos cegos em diversos países a partir do exemplo parisiense (GUADET, 1849). Nesta época, o Instituto conheceria um verdadeiro "progresso" na educação dos cegos com o desenvolvimento do alfabeto Braille e a projeção dada por Guadet aos debates sobre sua instrução, notadamente nos jornais que ele publicava. Assim, mesmo com todas as instabilidades e os períodos de declínio, o Instituto Nacional dos Meninos Cegos de Paris se tornaria uma referência mundial, bem como o Instituto de Surdos-Mudos de Paris. 


\section{O Imperial Instituto dos Meninos Cegos (1854-1890)}

O Imperial Instituto de Meninos Cegos, fundado no Brasil em 1854, tem sua origem diretamente relacionada ao poder de influência de Dr. José Francisco Xavier Sigaud, um dos médicos do Imperador D. Pedro II. Sigaud era um reconhecido médico francês que veio ao Brasil em 1825, fugindo da perseguição política antibonapartista. Seu interesse pela cegueira não vinha somente do fato de ser médico, mas principalmente por ter uma filha cega, Adèle Marie Louise Sigaud. Em busca de possibilidades de instrução para a sua filha, Sigaud recebe notícias sobre a primeira escola especializada para cegos criada em Paris e, em uma de suas viagens para a França, teria ido conhecer o instituto.

Concomitante a isto, estudava no Instituto Nacional dos Meninos Cegos de Paris o jovem cego brasileiro José Álvares de Azevedo, que permaneceu na escola francesa durante seis anos ininterruptos (entre 1844 e 1850), onde se formou com destacadas notas e premiações. Não encontramos fontes que nos digam ao certo se Sigaud teria conhecido José Álvares de Azevedo quando este estava estudando no Instituto Nacional dos Meninos Cegos de Paris ou na própria cidade do Rio de Janeiro. Independente disto, Azevedo passa a alfabetizar Adèle por meio do sistema Braille e eles decidem, conjuntamente, encaminhar um projeto ao Imperador para a fundação de uma escola para cegos baseada no instituto parisiense.

Com apoio de Couto Ferraz, que naquele momento ocupava o cargo de Ministro dos Negócios do Império, o Imperador decreta a criação do Imperial Instituto dos Meninos Cegos do Rio de Janeiro em 12 de setembro de 1854. Junto ao decreto, vem anexo um regulamento provisório para a instituição, que entraria em vigor naquele momento, sendo complementado ao final do mesmo ano, por um segundo regimento interno provisório.

Segundo Zeni (2005), a justificativa para a sua criação teria sido moral, no sentido de que a instrução deveria ser para todos, e civilizacional, visto que vários países já tinham escolas especializadas para cegos de acordo com o próprio Sigaud, em pouco mais de 140 instituições conhecidas. Além disso, as estatísticas de que os cegos no Rio de Janeiro do início do Império totalizavam cerca de 148 foram um argumento bastante relevante na aprovação da proposta.

O Instituto tinha, em seu primeiro regulamento, aberto 30 vagas para alunos de ambos os sexos com idade máxima de admissão aos 12 anos e com comprovação médica de cegueira total. Além disso, os que não trouxessem uma comprovação de pobreza deveriam 
pagar quatrocentos mil réis de pensão anual. Assim, a necessidade de o ensino ser gratuito, devido a maior parte de cegos serem pobres se contrapõe diretamente com a ideia de que a instituição deveria onerar o mínimo possível os cofres do Império, impasse que se resolve, em partes, com a limitação de apenas dez vagas para alunos que comprovassem pobreza. É importante ressaltar ainda que os cegos escravos não eram contemplados pelos benefícios da educação, uma vez que estes não eram livres e, portanto, não seriam considerados cidadãos brasileiros.

Sendo a idade máxima de admissão dos alunos 12 anos, era passível que estes ficassem no instituto até os 22, visto que o tempo máximo de permanência era de oito anos, prorrogáveis por mais dois, em caso de não conclusão dos estudos até o momento limite. Os professores teriam sido, primeiramente, trazidos de instituições já existentes na Europa. Os alunos que se destacassem nos estudos eram "preferidos para o cargo de repetidor que, no prazo de dois anos, passariam à condição de professor". Além disso, os repetidores também poderiam se tornar inspetores, aumentando as possibilidades de permanência no instituto. Assim, o ensino no Instituto Imperial de Meninos Cegos baseava-se no tripé música, trabalho e ciência, de modo a incentivar que os alunos mantivessem sua vida dentro do Instituto, ao invés de estimulá-los a garantir uma vida de forma independente.

Após a morte de José Francisco Xavier Sigaud, em 1856, assume a administração o Dr. Cláudio Luiz da Costa, que permaneceria no cargo até o ano de 1869. Cláudio Luís da Costa era um médico formado na Escola Médico-Cirúrgica da Corte e, enquanto servidor público, teria sido transferido para diversas províncias ao longo de sua carreira, vivendo uma vida instável (ZENI, 2005, p. 170-171). De acordo com Zeni (2005), não existem indícios de qualquer relação com os cegos antes de assumir a direção do instituto. Assim, o historiador conclui que Cláudio Luiz da Costa havia sido educado para pertencer as elites, vivenciava uma instabilidade em seu emprego, além de alguns sérios problemas de saúde, visando um cargo mais estável.

Quando Cláudio Luiz assumiu a direção do Instituto, teria encontrado uma série de irregularidades nas contas da administração anterior. Nos relatórios do ministro dos negócios do Império durante seu período à frente da instituição, ele sempre trouxe apontamentos bastante elogiosos sobre boa administração que Cláudio realizava no instituto. Em sua administração a disciplina teria se tornado mais rígida no instituto, com maior controle de gastos no sentido de um esforço de economia. Com isso, Cláudio Luiz 
fazia demandas constantes ao ministério acerca das verbas, e decidiu criar um patrimônio próprio para o instituto com vistas à uma verdadeira autonomia financeira, patrimônio este que se constituiria por meio de doações. Desse modo, Cláudio Luiz teria administrado o instituto com foco na disciplina e na ordem, contratando os funcionários necessários, negociando uma nova casa para abrigar a instituição e mantendo ainda o regimento da época da criação do instituto. Em 1869, com a sua morte, assume a direção interina Benjamin Constant.

Benjamin Constant teria entrado no Imperial Instituto dos Meninos Cegos como professor de matemática e ciências em 1862 (ZENI, 2005, p. 176). Cursou a escola militar, onde mais tarde teria sido professor. Ele se dedicava ao magistério, e já tinha lecionado também no Colégio Pedro II e na Escola Normal da Corte. (ZENI, 2005, p. 87). No ano seguinte a sua entrada no Imperial Instituto dos Meninos Cegos como professor, ele teria se casado com a filha de Cláudio Luiz da Costa, o que teria estreitado suas relações políticas com o antigo diretor e com o próprio Instituto.

Benjamin Constant foi uma importante figura política brasileira nos finais do Segundo Reinado e no início do período republicano. Vinha de uma família com poucos recursos, seu pai ex-tenente do Corpo de Artilharia da Marinha Portuguesa, teria se tornado professor ao mudar-se para o Brasil. Em meio às dificuldades financeiras, ele garantia o sustento da família com suas aulas. Benjamin Constant teria se filiado a diversas entidades de natureza assistencial, como Montépio Geral, Sociedade Auxiliadora das Artes Mecânicas e Liberais e Beneficentes, Sociedade Brasileira de Beneficência, Sociedade Beneficência Perfeita Amizade, Imperial Irmandade da Santa Cruz dos Militares, Associação Protetora da Infância Desamparada, entre outras.

Isso evidencia seu interesse nas ações de beneficência, de modo que não podemos deixar de pensar em como esse tipo de relação se estendia no seu interesse pelo ensino dos cegos. Segundo Zeni (2005), Benjamin Constant já teria encontrado o instituto com bases firmadas, "mas carecendo muito de dedicação daquelas pessoas que por ele lutavam. Foi ele mais um destes abnegados, justificando com seu trabalho em prol dos cegos a consideração de que o Instituto representou sua ação mais importante no campo da assistência" (p. 119). Assim, ele se preocupou fundamentalmente em expandir a educação dos cegos pelo Brasil, ramificando o instituto pelas províncias do território nacional, com vistas a torna-lo autossuficiente. 
Além disso, ele teria se preocupado centralmente com a necessidade de conceber um regulamento definitivo para 0 instituto, que até então estava regido pelo regimento provisório da fundação de 1854. Ademais, os relatórios nos mostram sua dedicação na luta pela transferência do instituto para o prometido prédio na antiga praia da saudade, que seria fundamental para a sua expansão ao maior número de cegos do Império; proposta que se concretizaria somente em 1891. Assim, Benjamin Constant foi uma figura central na luta em prol da melhoria das condições de vida dos cegos; deixando a direção somente vinte anos depois, com a Proclamação da República Brasileira, para assumir a pasta da Instrução Pública, de onde seguiria olhando pela instituição de cegos até a sua morte.

\section{O Imperial Instituto dos Surdos-Mudos (1856-1890)}

O Imperial Instituto dos Surdos-Mudos, por sua vez, foi fundado oficialmente três anos após a criação do Imperial Instituto de Meninos Cegos. Entretanto, diferentemente dos cegos, ele não teve apoio inicial do Império, partindo de uma iniciativa de E. Huet. O mistério envolvendo a figura de Huet se coloca para esta investigação, bem como para toda a historiografia que tem se dedicado ao tema, como um empecilho para a compreensão dos motivos que teriam levado à fundação do instituto. Supostamente, Huet teria sido um surdo francês que, tendo estudado e lecionado no Instituto Nacional de Surdos-Mudos de Paris e dirigido o Instituto de Surdos-Mudos de Bourges, almejava criar um instituto similar no Brasil para beneficiar os surdos que aqui viviam.

Contudo, a partir de uma carta encontrada nos arquivos históricos do Instituto Nacional de Jovens Surdos de Paris, levantamos uma nova hipótese sobre a criação do instituto brasileiro. Tal carta partiu do Consulado Geral da França no Brasil e do Ministério dos Casos Estrangeiros ao Ministre des Affaires Étrangers à Paris, do ano de 1826. Nesta carta, o Consul Geral da França no Brasil comunicou ao Ministro dos Casos Estrangeiros de Paris que o Imperador do Brasil, "apreciando tudo o que possa esclarecer sobre os estabelecimentos úteis a serem criados em seu Império, recebeu com muito interesse a comunicação direta que eu the fiz do programa relativo ao estabelecimento de surdos e mudos (...)". Continuava dizendo que:

O Brasil, sendo um país novo onde tudo está ainda por se formar, não tem nenhum estabelecimento que tenha relação a este criado pelo abade de L'Épée e que dá tanta honra à França. Eu não sei mesmo de nenhum indivíduo que já tenha feito observações ou recolhido fatos dessa natureza que mereçam a atenção destes que se dedicam na França para o alívio dos surdos e mudos (GESTAS, 1826). 
Deste modo, supomos que a correspondência enviada da França ao Brasil, a qual esta carta responde, demandava de nossas autoridades se existia no Brasil algum estabelecimento de ensino destinados aos surdos, comunicando sobre a existência do Instituto Nacional de Surdos-Mudos de Paris. Podemos concluir, desse modo, que o Ministério dos Estrangeiros francês estaria fazendo um trabalho de divulgação do Imperial Instituto de Surdos-Mudos que provavelmente se estendia a outros países que não somente o Brasil.

Segundo o primeiro relatório do Ministro dos Negócios do Império acerca do Instituto de Surdos-Mudos, referente ao ano de 1856, o Imperial Instituto dos Surdos-Mudos teria sido fundado no dia $1^{\circ}$ de janeiro de 1856 , em uma das salas do colégio de Vassimon. Teria iniciado os trabalhos com três alunos, dois subsidiados pela província do Rio de Janeiro e um mantido por seus próprios meios. Ele seria aberto para alunos dos dois sexos, separados fisicamente, e lhes forneceria, além de moradia e alimentação, a instrução primária e secundária, bem como a religião e a moral, noções de artes e de ciências. A responsabilidade pela educação das meninas seria atribuída a esposa do diretor.

O ministro anuncia que, visto o zelo e inteligência investidos nesta "nobre" tarefa, seria criada uma comissão promotora do nascente instituto, formada por homens distintos. Seriam eles: os marqueses de Abrantes, de Monte Alegre e de Olinda, o conselheiro de estado Euzébio de Queiróz Coitinho Mattoso Camara, o D. abade de São Bento, o prior do convento do Carmo, o Dr. Manoel Pacheco da Silva e o cônego Joaquim Caetano Fernandes Pinheiro, que serviria também de secretário.

A primeira menção ao Instituto dos Surdos-Mudos no âmbito legislativo vem da lei no 939 de 26 de setembro de 1857 (artigo 16, inciso 10). Esta lei nos aponta, basicamente, que o subsídio oficial que o Império passa a fornecer ao Instituto. Na íntegra, ela determina "conceder, desde já ao Instituto dos Surdos-Mudos, a subvenção annual de 5:000\$000, e mais dez pensões, também annuaes, de $500 \$ 000$ cada huma, a favor de outros tantos surdos-mudos pobres, que nos termos do Regulamento interno do mesmo Instituto, foram aceitos pelo Diretor e Comissão e approvados pelo Governo" (BRASIL, 1857). Assim, o instituto se transforma em uma espécie de parceria entre o âmbito público e o privado, sendo financiada pelo Governo e pelas doações da Igreja, e administrada por um particular, supervisionado pelo Império. Nos anos seguintes, o número de alunos do instituto vai 
aumentando progressivamente, em particular devido às novas pensões fornecidas pelo governo Imperial.

Os alunos para se matricularem, precisavam ter entre sete e 16 anos e apresentar somente um certificado de vacinação. Em um primeiro momento, eram aceitas também as alunas, que, posteriormente, seriam excluídas do direito ao estudo no Instituto por algumas décadas, do mesmo modo como ocorrera no Instituto Nacional de Surdos-Mudos de Paris. Assim como no Imperial Instituto de Meninos Cegos, eram destinadas pelo Imperador pensões para garantir a educação gratuita de apenas dez das 30 vagas oferecidas. Com isto, cerca de $30 \%$ das vagas permaneceram desocupadas nos primeiros anos após a fundação, como aponta o registro de matrícula dos alunos surdos do Instituto em 1858.

O ministro menciona ainda que o Instituto já tinha uma série de dívidas, que estavam sendo sanadas pouco a pouco com o auxílio do governo, diminuindo seu déficit mensalmente. Em 1858, ele afirma que as dívidas feitas por Huet estariam completamente pagas. Contudo, uma das reclamações que persiste no relatório dos ministros é a falta de verbas para dar ao instituto o "nível" obtido por instituições da mesma natureza em outros países, pedindo, inicialmente, a elevação da pensão de 5:000\$000 a 11:000\$000. É devido a essa relação dúbia que o instituto apresenta perante o seu fundador e o Governo que os conflitos com Huet começam a ficar aparentes, culminando na saída do diretor e na "compra" da Instituição pelo Império.

No relatório de 1860, o ministro traz o manifestado desejo de Huet de se retirar para a Europa, com o discurso que o instituto já estaria fundado de modo que não seria mais necessária a sua presença. Para isto, como ele tinha o direito a propriedade do estabelecimento, declarou a comissão inspetora que preferia deixa-la ao governo ao invés de vendê-la a um particular, uma vez que este se comprometesse com o pagamento de uma pensão anual de 2:000\$000, que permanecesse para a sua mulher e para os seus filhos. Não está claro, de fato, as razões que teriam levado Huet a pedir a saída do instituto, visto que estamos tratando unicamente da visão do Ministério sobre ela. O ministro nos incita a pensar que esta atitude de Huet teria se configurado como um "golpe" financeiro no Império, uma vez que este já financiava quase todos os gastos do instituto e ainda havia quitado todas as dívidas feitas por Huet.

Desse modo, no ano seguinte, teria sido celebrado pela comissão inspetora com Huet, no contrato datado de 10 de abril de 1861 , a sua saída do instituto, mediante o pagamento 
da quantia de 3:494\$021, ficando o instituto, assim, pertencendo ao governo e continuando a cargo da mesma comissão promotora. A direção do instituto foi confiada pela comissão ao padre Frei João de Nossa Senhora do Carmo. Nos anos que se seguiram à saída de Huet, ficou a promessa de formar Manoel da Magalhães Couto, aluno destacado dos primeiros anos de existência do Instituto dos Surdos-Mudos, no Instituto de Paris, voltando com uma formação apropriada para administrar o Instituto. $O$ Império financiou seus estudos, de modo que ele retornou ao Brasil em 1863 e logo assumiu a direção da instituição.

Assim, no período que compreende o Segundo Reinado brasileiro, o Instituto de Surdos-Mudos teve cinco diretores, com destaque para Tobias Rabello Leite, que fica à frente do cargo até a sua morte em 1896, por quase 30 anos. Entre seus feitos principais ao longo de sua gestão, estavam 1) a instituição do ensino profissionalizante, com as oficinas de encadernação, de sapateiro e uma pequena escola agrícola que ele teria criado, o que garantiria ao surdo uma possibilidade de sobrevivência fora do Instituto, diferentemente do incentivo de permanência dado pelo Imperial Instituto de Meninos Cegos; 2) a tradução de livros franceses utilizados no Instituto de Jovens Surdos de Paris, divulgando e orientando, em âmbito nacional, a educação de surdos; 3) obras no edifício que abrigava o instituto, que teriam sanado os graves problemas de higiene existentes anteriormente; 4) e a restrição dos estudos para o sexo masculino, proibindo a instrução de meninas no Instituto desde 1874.

\section{Considerações finais}

Como já mencionamos ao longo desse estudo, a criação das quatro instituições está baseada em uma lógica específica entre a iniciativa individual de filantropos e a responsabilização estatal. Nesse sentido, consideramos fundamental entender as motivações de seus instituidores na fundação das escolas e observar como a "política dos favores" se mantém ao longo de todo o século XIX. Assim sendo, explicitamos a produção historiográfica francesa, que, até o presente momento, identifica o interesse do abade de L'Épée e de Valentin Haüy na notabilidade social: estes grandes filantropos da sociedade parisiense buscavam se tornar instituidores com intuito de pertencer às "redes de sociabilidade da nebulosa filantropia" e "por amor a humanidade", ligando-se para além de suas clivagens religiosas ou políticas (DUPRAT, 1995). Assim, eles tornariam-se os primeiros instituidores para surdos e cegos no mundo a publicizarem seus métodos e 
abrirem escolas que fossem acessíveis não somente para os pertencentes as elites daquela sociedade.

Em relação ao Brasil, a discussão relativa à fundação dos institutos ainda segue em aberto, a nosso entender, em alguns aspectos. No caso do Imperial Instituto dos Meninos Cegos a compreensão dos interesses pessoais e civilizacionais de José Sigaud, aliado ao cego José Álvares de Azevedo, é explícita, porém, no caso do Imperial Instituto dos SurdosMudos não há ainda consenso sobre quais razões teriam motivado Huet a tentar criar fundar uma escola no Brasil, tendo em vista os dados explicitados ao longo deste estudo.

Potencialmente, a França tinha pretensões de difundir as instituições para surdos pelo mundo, e pode, inclusive, ter oferecido auxílio para o governo imperial criar uma instituição similar no Brasil. Todavia, só poderemos afirmar isto com convicção quando encontrarmos as outras correspondências sobre o assunto trocadas entre estas autoridades. Alguns dos estudiosos que se dedicaram a escrever sobre a história do Imperial Instituto de SurdosMudos afirmam que Huet teria sido recomendado pelo Ministro de Instrução Pública da França, com apoio do embaixador francês no Brasil. (LEMOS, 1981, p. 41). Contudo, não encontramos documentação que comprovasse essa intermediação oficial da vinda de Huet, mas acreditamos que seja sim uma possibilidade visto o interesse francês expresso nesta correspondência.

Neste sentido, é necessário prosseguir em torno da busca por esta documentação para que possamos discutir com maior profundidade às motivações que teriam trazido Huet ao Brasil. Todavia, trata-se de uma difícil tarefa: ainda não encontramos rastros de sua vida anterior à sua chegada ao Brasil. Primeiramente, posto que não foram encontradas ainda fontes sobre ele no Instituto Nacional de Jovens Surdos de Paris. Além disso, o mistério em torno de seu nome é um empecilho na busca por informações sobre ele.

Assim sendo, não podemos desprezar a possibilidade desta articulação entre a França e o Brasil ter sido realizada em meios oficiais também no caso dos cegos. Entretanto, a correspondência entre M. Guadet, diretor do Instituto Nacional de Meninos Cegos de Paris à época e José Sigaud, revela as relações entre os instituidores e o interesse de Sigaud em saber tudo sobre o funcionamento do instituto parisiense, com vistas à implementação em sua escola para cegos. Assim, se por um lado essa intermediação pode ter ocorrido também entre as autoridades da época, sobretudo, entre os ministros do estrangeiro, Sigaud teria pessoalmente garantido as ligações entre o 
Instituto Nacional de Meninos Cegos de Paris e o Imperial Instituto dos Meninos Cegos do Rio de Janeiro.

Evidentemente, essas ligações entre Paris e Rio de Janeiro teriam perpassado, mais do que as relações oficiais e burocráticas do Ministério, o nível de interesse dos instituidores que estiveram à frente dos estabelecimentos. Desse modo, se por um lado os interesses e a organização geral de funcionamento destes institutos nos parecem bastante similares nos anos que se seguem à suas fundações, inferimos que estas relações tenham se perdido com o passar das décadas, uma vez que apropriada culturalmente a concepção geral da instituição, as escolas brasileiras passariam a atuar em uma dinâmica específica ligada aos interesses do projeto nacional que estava se constituindo. Contudo, indubitavelmente as instituições permaneceriam ligadas por muito tempo no que diz respeito à apropriação dos métodos de instrução para surdos e cegos desenvolvidos, sobretudo, na Europa, e pela lógica de beneficência que se perpetuaria nos institutos brasileiros até o final do século XIX.

\section{Referências}

Archives du Musée Valentin Haüy. Carta de J. Sigaud a M. Guadet sobre a fundação do Instituto de Meninos Cegos do Rio de Janeiro, 1854.

Archives historiques de l'IJNS. Lettre du Comte de Gestas, 1826.

Archives historiques de l'INJA. Livre de distribution des prix de I'Institut National des Jeunes Aveugles, 1855-1890.

BRASIL. Lei no 939 de 26 de setembro de 1857. Coleção das Leis do Império do Brasil. Atos do poder legislativo.

BERNARD, Yves. L'esprit des sourds: les signes de l'Antiquité au XIXe siècle. Paris : les éditions du Fox, 2014.

BÉZAGU-DELUY, Maryse. L'abbé de l'Epée : instituteur gratuit des sourds et muets (17121789). Éditions Seghers, Paris, 1990.

BUTON, François. Les Corps saisis par l'État : l'éducation des sourds-muets et des aveugles au XIXe siècle : contribution à la socio-histoire de l'État, 1789-1885. Thèse de Doctorat en Histoire Moderne. Paris, EHESS: 1999.

DELAPORTE, Yves. L'école des sourds : Encyclopédie historique des institutions françaises. Paris: Éditions du fox, 2016.

DETIENNE, Marcel. Construir Comparáveis, In: Comparar o incomparável. São Paulo: Ideias e Letras, 2004. 
DIDIER-WEYGAND, Zina. Vivre sans voir : Les aveugles dans la société française, du Moyen-Age au siècle de Louis Braille. Paris : Créaphis, 2003.

DUPRAT, Catherine. Le temps des philanthropes: Tome 1, La philanthropie parisienne des Lumières à la monarchie de Juillet. Paris : CTHS, 1995.

GUADET, Joseph. Institut des jeunes aveugles de Paris, son histoire. Paris, E. Thunot et Company, 1849.

GUILBEAU, Edgard. Histoire de L'Institution Nationale Des Jeunes Aveugles. Paris: Belin Frères, 1907, p. 19.

HENRI, Pierre. La vie et l'œuvre de Louis Braille. Paris, Presses Universitaires de France, 1952.

HENRI, Pierre. La vie et I'œuvre de Valentin Haüy. Paris, Presses Universitaires de France, 1984.

LEMOS, Edison Ribeiro. Educação de excepcionais: evolução histórica e desenvolvimento no Brasil. Tese apresentada para a habilitação à Livre Docência em História da Educação, Universidade Federal Fluminense, 1981, p. 41.

JANNUZZI, Gilberta de Martino. A educação do deficiente no Brasil: dos primórdios ao início do século XXI. Campinas (SP): Autores Associados, 2004.

L'ÉPÉE. Charles-Michel (de). Institutions des Sourds et Muets par la voie des signes méthodiques. Paris, Nyon, 1776.

MAZZOTTA, Marcos. Educação Especial no Brasil: história e políticas públicas. São Paulo: Cortez, 2001.

Museu Imperial. Arquivo da Casa Imperial do Brasil (POB). Maço 122 - Doc. 6078. Relatório, em francês, de Ernest Huet, do Instituto de Surdos-Mudos [da França?] a d. Pedro II, imperador do Brasil, sobre a criação do Instituto de Surdos-Mudos no Brasil. Rio de Janeiro, 22/06/1855.

PRESNEAU, Jean-Réné. Le son à la lettre: l'éducation des sourds et muets avant l'abbé de I'Épée, In KARACOSTAS, Alexis (dir.). Le pouvoir des signes. Paris, INJS, 1990.

REILY, Lucia Helena. Educação Inclusiva: linguagem e mediação. Campinas (SP): Papirus, 2004.

ROCHA, Solange. O INES e a educação de surdos no Brasil: aspectos da trajetória do Instituto Nacional de Educação de Surdos em seu percurso de 150 anos. Rio de Janeiro: INES, 2007.

SOARES, Maria Aparecida Leite. A educação do surdo no Brasil. Campinas, SP: Autores Associados Bragança Paulista, SP, EDUSF, 1999. 
SOFIATO, Cássia. Geciauskas. Do desenho à litografia: a origem da língua brasileira de sinais. Tese (doutorado). Universidade Estadual de Campinas, Instituto de Artes. Campinas, SP: [s.n.], 2011.

VIDAL, Diana Gonçalves. História da Educação Comparada: reflexões iniciais e relato de uma experiência. História da Educação, Pelotas (RS), ASPHE/UFPel, 2001, n. 10, p. 3142.

ZENI, Maurício. Os Cegos no Rio de Janeiro do Segundo Reinado e Começo da República. Niterói, Universidade Federal Fluminense, 2005.

\section{Correspondência}

Roberta Baessa Estimado - Universidade de São Paulo. Avenida da Universidade, 308, Sala 218, Bloco B. CEP: 05508-040. Butantã, São Paulo, Brasil.

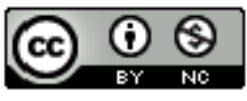

This work is licensed under a Creative Commons Attribution-NonCommercial 4.0 International (CC BY-NC 4.0) 